\title{
El primer parque urbano de Zaragoza: el Parque Pignatelli, historia y diseño
}

\author{
The first urban park in Zaragoza: Pignatelli park, \\ history and design
}

\author{
LAURA RUIZ CANTERA \\ Doctoranda en Historia del Arte. Becaria FPU. Universidad de Zaragoza \\ lruizcantera@gmail.com
}

Recibido: 10/03/2016

Aceptado: 28/06/2016

\section{Resumen}

El presente artículo se centra en el estudio de la historia del primer parque construido en Zaragoza, el parque Pignatelli, cuyo proyecto originario fue redactado por el arquitecto municipal, Ricardo Magdalena en el año 1892. Se analiza la génesis del parque y la evolución del mismo hasta su última reforma en 1985 desde un enfoque multidisciplinar, en donde se aúnan aspectos formales, estilísticos, históricos, sociológicos y geográficos. A través de su historia, se constata como su construcción estuvo marcada por los intereses económicos, la opinión pública, la colaboración ciudadana y sobre todo, por los deseos de equiparar a Zaragoza con otras capitales españolas y europeas mediante la introducción de un espacio verde público, símbolo de prestigio y progreso de las ciudades contemporáneas. El objetivo principal de esta investigación es el de dar a conocer y analizar el tema de la introducción de los primeros parques urbanos en la ciudades españolas, entendidos como la proyección arquitectónica y artística del paisaje, a partir de este ejemplo concreto.

\section{Palabras clave}

Urbanismo contemporáneo, parque urbano, naturaleza, diseño, Zaragoza, parque Pignatelli. 


\begin{abstract}
This article has focused on the study of the history of the first park constructed in Saragossa, the Pignatelli park, whose original project was designed by the municipal architect, Ricardo Magdalena in 1892. It is analyzed the genesis of the park and its evolution until the last remodeling in 1985 from a multidisciplinary approach stylistic, historical, sociological and geographical aspects. It is possible to state its construction which was marked by the economic interests, the public opinion, the civil collaboration and especially, by the desires to compare Zaragoza with other Spanish and European capitals by means of the introduction of a green public space, symbol of prestige and progress of the contemporary cities. The main objective of this research is to publicize and discuss the issue of the introduction of the first urban parks in the Spanish cities, understood as the architectural and artistic design of the landscape, from this particular example.
\end{abstract}

\title{
Keywords
}

Contemporary urbanism, urban park, nature, design, Zaragoza, Pignatelli park.

Referencia normalizada: RUIZ CANTERA, LAURA (2016): “El primer parque urbano de Zaragoza: el parque Pignatelli, historia y diseño". Arte y Ciudad. Revista de Investigación, no 10 (octubre), págs. 159-186. Madrid. Grupo de Investigación Arte, Arquitectura y Comunicación en la Ciudad Contemporánea, Universidad Complutense de Madrid.

Sumario: 1.- Introducción. 2.- Directrices generales del ensanche meridional de Zaragoza. 3.- El parque Pignatelli (1892-1985). 3.1.- Antecedentes (1850-1892). 3.2.- El proyecto para la construcción del parque (1892-1900). 3.3.- La consolidación del espacio (1900-1940). 3.4.- Las últimas reformas (1940-1985). 4. Conclusiones. 5. Bibliografía.

\section{Introducción.}

El término de "parque urbano" admite una variedad de definiciones por la pluralidad de disciplinas que se cruzan para su estudio histórico (origen, evolución, valoración, significado, sociedad...), teniendo en cuenta otros aspectos técnicos como la localización geográfica, usos aplicados y el diseño. Los parques urbanos se pueden considerar espacios libres polivalentes acotados en la ciudad que cumplen una doble función, tal y como señala J. M. Alonso, "como integradores de la naturaleza en la ciudad y como espacios al servicio del tiempo libre cotidiano" (Alonso Velasco, 1971: 76) A partir de estas premisas todos los campos que intervienen en el proceso de creación de un parque urbano se 
ponen en funcionamiento para alcanzar estos objetivos con resultados que varían en función de las necesidades e intereses. Es una definición inmutable que puede aplicarse al concepto del parque desde su nacimiento hasta la actualidad, teniendo en cuenta las mejoras que ha sufrido su espacio físico al compás del progreso humano, así como las interpretaciones y valoraciones sobre su concepto. No obstante, el nacimiento del parque urbano, entendido como un pulmón verde de la ciudad y una extensión destinada al disfrute y la evasión pública, no se convirtió en una realidad hasta mediados del siglo XVIII en el seno de la ciudad industrial, señalada como causante de todos los males.

En Zaragoza, la teoría reivindicadora del espacio natural como agente beneficioso para la concentración urbana fue conocida en las mentes ilustradas zaragozanas desde el siglo XVIII y hasta fines del siglo XIX, las zonas verdes se localizaban en arboledas naturales, paseos flanqueados por árboles, viveros municipales y jardines en puntos privilegiados de la ciudad, tanto públicos como privados. La idea de dotar a la ciudad con un parque urbano a emulación de las grandes capitales europeas, nació durante la segunda mitad del siglo XIX con la finalidad de cubrir las necesidades de esparcimiento de la población. Tras diferentes iniciativas que no llegaron a ejecutarse, se eligió un espacio situado en el barrio rural de Torrero al Sur, predilecto por los zaragozanos en días de festividad, concretamente un terreno triangular junto a la subida de Cuellar, conocido como "graveras de Torrero" o "de Cuellar". A partir de aquí comienza la historia del primer parque constituido en Zaragoza, el parque Pignatelli, prolongándose durante el siglo XX con luces y sombras, hasta la última gran reforma acometida en el año 1985.

\section{Directrices generales del ensanche meridional de Zaragoza.}

Para el estudio del parque Pignatelli y su entorno es necesario esbozar unos planteamientos generales histórico urbanísticos del ensanche meridional de Zaragoza - espacio en el que se localiza-, para comprender bajo una perspectiva general de la ciudad y del barrio las diversas situaciones y acontecimientos que se dieron en esta zona específica.

La extensión de la ciudad de Zaragoza hacia el Sur estuvo motivada por una serie de hitos urbanísticos decisivos que permitieron la consolidación de una amplia zona que geográficamente se desarrollaba más allá de los límites de la ciudad histórica, desde la margen derecha del Huerva hasta el monte de 
Torrero. El núcleo originario del ensanche decimonónico fue el barrio rural de Torrero y su eje vertebrador, el llamado homónimamente "camino de Torrero", cuyo trayecto desde fines del XVIII nacía en el puente de Santa Engracia y culminaba en las aguas del Canal Imperial.

El origen del barrio de Torrero hay que unirlo al proyecto del Canal Imperial, el cual se sitúa entre los años 1528 y 1529 bajo el reinado del emperador Carlos V, quien buscaba proporcionar agua de riego a Aragón y Navarra. La obra quedó paralizada en la localidad de Garrapinillos durante doscientos años y con el ascenso al trono de Felipe V, la idea inicial de construir una acequia se sustituyó por la de un canal de riego y de navegación. A mediados del siglo XVIII, durante el periodo de la Ilustración, se afianzó la empresa del Canal con la intencionalidad de que formara parte de una red de canales que comunicasen diversos puntos de España. Con el cese de la compañía encargada de las obras, la continuación de las mismas se confió a Ramón Pignatelli, el verdadero artífice de la traída de las aguas a la ciudad, con el título de Protector del Canal en 1772 y a los ingenieros Gil Pin, Sánchez Boort y Agustín Betancourt. En 1784 llegaron las aguas a través del Canal Imperial a Zaragoza y dos años después se inauguraron los puertos de Casablanca y Torrero. A partir de este momento el Canal Imperial amparó la formación del barrio de Torrero.

Partiendo de las informaciones aportadas por el Conde de Sástago en 1796, el vínculo con la ciudad se establecía por el puente de América, que permitía la comunicación con "pueblos, viñedos y dehesas superiores", desde donde se observaban "montes y huertas" (Conde de Sástago, 1796). También, en el entorno del Canal se localizaban una serie de instalaciones de carácter artesanal y fabril, así como la iglesia de San Fernando, construida en 1799 por Tiburcio del Caso. Otras construcciones significativas eran el puente de América, construido en 1815, tras él nacía un camino, la actual avenida de América, que comunicaba con el cementerio de Torrero, inaugurado en 1834. Debido a la consideración que habían alcanzado los paseos y las arboledas en la ciudad, frente a la iglesia de San Fernando se situaron una pequeña plazoleta ajardinada y un surtidor. Un conjunto que se integraba en la playa de Torrero, junto al Canal y que se convirtió en un lugar predilecto por los habitantes en las festividades por su carácter pintoresco. Estos jardines fueron proyectados por la administración del Canal Imperial a mediados del siglo XIX, responsable de este tipo de obras en Zaragoza. Perseguían con ello establecer un contacto entre hombre y naturaleza bajo principios higienistas. 
Estos acontecimientos y construcciones fueron el punto de partida para la urbanización de la zona, la cual se orientará a las clases populares a causa del bajo precio del suelo en comparación con el casco urbano y los ensanches que se proyectarán a comienzos del XX, sometidos a la especulación. Esta situación dio lugar a la aparición de las primeras barriadas obreras, compuestas por edificaciones autoconstruidas que permitieron el acceso a la vivienda en propiedad. También durante la primera mitad del XIX, el Canal participó en el proceso de industrialización de la ciudad como fuente de energía hidráulica. De hecho, la Guía de Zaragoza de 1860 (pp. 456-462) describe la playa de Torrero rodeada de industrias, almacenes y talleres; en cuanto al monte de Torrero, afirma que contenía una "pequeña población". (Fig. 1)

Fig. 1. Plano que manifiesta todas las obras construidas $y$ proyectadas en el Monte Torrero (Tiburcio del Caso, 1796) / Esquema de las obras (elaborado por Isabel Yeste).
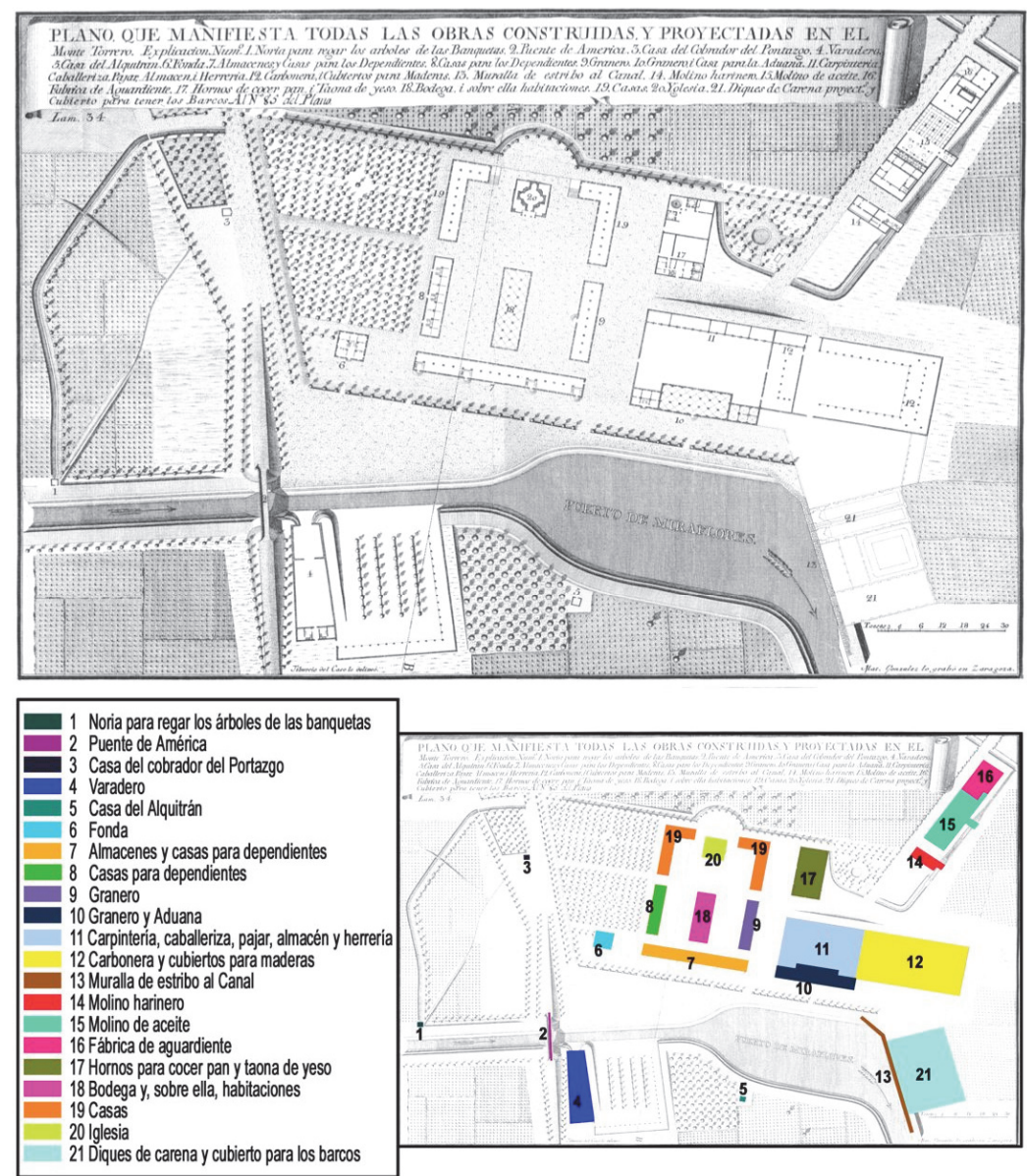
El interés del municipio por crear paseos como lugares de esparcimiento y la intención de conectar y ocupar la zona Sur de Zaragoza, se tradujo en una de las intervenciones urbanísticas de mayor prestancia, la formación del Salón de Santa Engracia - paseo de la Independencia - . El origen del paseo se encuentra en la Zaragoza napoleónica (1809-1813), cuando Joaquín Asensio proyectó la construcción del inicialmente denominado paseo Imperial entre la plaza de San Francisco - plaza de España - y la puerta de Santa Engracia. Durante el reinado de Fernando VII, esta iniciativa fue retomada por Martín Garay en 1815, quien ordenó el espacio y concibió un paseo arbolado que finalizaba con una nueva puerta, tras la que se construyó una "glorieta" ajardinada. En la década de los treinta Tiburcio del Caso llevó a cabo la remodelación del entorno y con Isabel II se planteó la terminación del paseo tomando como modelo la parisina Rue Rivoli bajo las directrices de los arquitectos Yarza y Gironza, quienes también dieron forma oval a la Glorieta de Pignatelli. En 1857 la Diputación de Zaragoza encargó al escultor Antonio Palao un monumento dedicado a Ramón Pignatelli para ser colocado en la Glorieta y fue inaugurado el 24 de junio de 1859. La glorieta pasó a denominarse así Glorieta de Pignatelli - plaza de Aragón-, un lugar de paseo preferente para los habitantes.

La celebración de la Exposición Aragonesa de 1868 en la glorieta de Pignatelli fue otro de los hitos que impulsó la urbanización de la zona Sur de Zaragoza y la formación del llamado barrio de Canfranc. Tras su clausura en 1874, los edificios de la exposición fueron derribados y un año después Segundo Díaz redactó un proyecto de parcelación de la glorieta. La moderna plaza se construyó a partir de un edificio significativo, la nueva Capitanía General - concluida en 1892- y de una serie de hotelitos cuyas fachadas reflejaban la elegancia y el nivel social de sus moradores (Vázquez Astorga y Yeste Navarro, 2001: 750). La obra se completó con la construcción de una nueva puerta de Santa Engracia, en línea con el paseo de la Lealtad - de Pamplona-, la cual sería derribada en el año 1904 y con ella, la barrera que impedía la expansión de la ciudad hacia el Sur (Yeste Navarro, 2007: 666). Tanto el paseo de la Independencia, como la plaza de Aragón, son resultado de un proceso continuo en el que se conforma primero un espacio de paseo y luego las edificaciones que lo rodeaban. 
Pero sin duda la vía de mayor relevancia del ensanche finisecular del siglo XIX fue el camino de Torrero, actual paseo de Sagasta. En la segunda mitad del siglo XIX el camino de Torrero se prolongaba desde el puente de Santa Engracia hasta el Canal, siguiendo un trazado recto, el trayecto se quebraba por los desniveles existentes en lo que se denominó subida de Cuellar, la cual concluía su recorrido en las playas de Torrero. A partir de Cuellar se abrían tres vías: la que se dirigía hacia Torrero - actual paseo de Cuellar-, el paseo Ruiseñores hacia el Oeste y una senda en el centro de las vías anteriores, hoy integrada en el interior del parque Pignatelli.

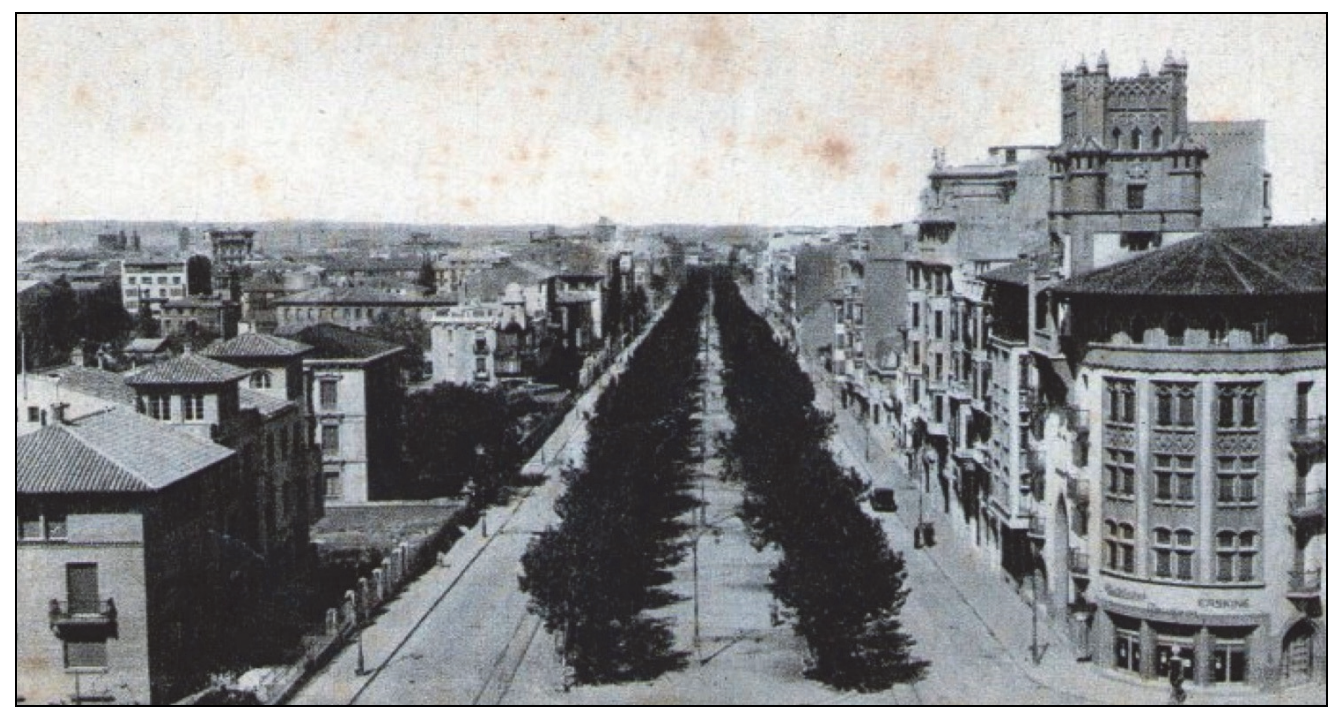

Fig. 2. Paseo de Sagasta a comienzo del siglo XX [A.M.Z]

El camino de Torrero estaba constituido por un paseo central por donde circulaban carruajes y tranvías y andenes laterales para los peatones y cada una de estas zonas quedaba separada del resto por una doble fila de arbolado. Flanqueando sus márgenes se levantaron casas de recreo, torres e industrias (Hernández Martínez, 1991-1992: 436). En 1885 se instaló la línea del tranvía de tracción animal que permitía la comunicación entre la ciudad y las afueras y la línea se electrificaría en 1902 (Fig. 2). La notoriedad alcanzada por el paseo hizo que ya en 1885 se aprobara un proyecto de reforma con la idea de prolongarlo hasta el Canal Imperial; en 1900 debido al crecimiento incontrolado de las edificaciones se redactó otro para su alineación que 
también afectaba a su entorno (camino del Sábado, paseo de las Damas etc.); y de nuevo en 1922 se acometió su reforma con la introducción de un andén central arbolado y dos paseos laterales; una vegetación que había sido sustituida por el pavimento años atrás. Realmente al auspicio de este paseo surgieron otras calles próximas como la de la Paz, la del Arca - actual calle Bolonia - o Lagasca y en definitiva toda la zona comprendida hasta el paseo de Cuellar.

A principios del siglo XX el ensanche hacia el Sur se fue progresivamente consolidando a través de reformas y mejoras puntuales como el ya comentado proyecto del paseo de Sagasta (1900), la alineación del paseo de Ruiseñores (1903), la construcción del nuevo puente de América (1903), el proyecto de un parque en el Cabezo de Buenavista (1903), la explanación de las graveras de Torrero (1904), así como todo lo relativo a la instalación de infraestructuras (alumbrado, alcantarillado, pavimentación, etc.).

En los posteriores proyectos y anteproyectos de ensanche se pretendió controlar el crecimiento del área meridional, ejemplos de éstos son las propuestas presentadas en 1906 por Ricardo Magdalena y Dionisio Casañal o el plan de 1921 - aprobado en 1925- redactado por Miguel Ángel Navarro, este último a diferencia del primero afectaba directamente a una amplia zona del Sur de Zaragoza. De hecho, concretó los nuevos focos de interés y de expansión del ensanche en la zona Sureste de Zaragoza, siendo dos las actuaciones más trascendentales: la urbanización de la Gran Vía con motivo del cubrimiento del río Huerva y la construcción del parque en el Cabezo de Buenavista. También en este plan, el Sur zaragozano se dividió en dos zonas de ensanche, Miralbueno (desde la Gran Vía hasta el parque) y Miraflores (desde el Huerva hasta el paseo de Sagasta y su entorno).

El primitivo eje del ensanche, el paseo de Sagasta y su prolongación por el paseo de Cuellar quedó ceñido por el afianzamiento de los llamados barrios particulares (San José, Torrero, Monforte, Acacias...) a consecuencia del crecimiento poblacional de la ciudad. A partir de este momento y una vez urbanizado el primer ensanche, los sucesivos proyectos tratarán de regularizar y urbanizar los nuevos puntos de expansión de la ciudad y también de mejorar y dignificar el casco histórico. 


\section{El parque Pignatelli de Zaragoza (1892-1895).}

\subsection{Antecedentes (1850-1892).}

Desde mediados del siglo XIX el terreno en el que hoy en día se encuentra localizado el parque Pignatelli fue ocupado por torres - casas asociadas al trabajo agrícola - cuyos campos de cultivo formaban una superficie triangular. La torre de Blasco, después de Mariano Judez, era una de las más destacadas de la zona. Esta superficie en forma de triángulo era definida y delimitada por el paseo de las Acerolas -desde 1876 paralelo a los depósitos de agua de Torrero-, la subida de Cuellar, donde surgía un camino cuyo trazado se prolongaba hasta el Canal Imperial y que, en 1900 se conocería como avenida del Siglo XX (hoy en día paseo de Cuellar). Este camino era la continuación del paseo de Torrero o de Sagasta, establecido a finales del siglo XVIII con motivo de la inauguración del Canal Imperial, siendo cedido después su uso por esta institución al Ayuntamiento de Zaragoza en el año 1852 para su correcta conservación (Fig. 3).

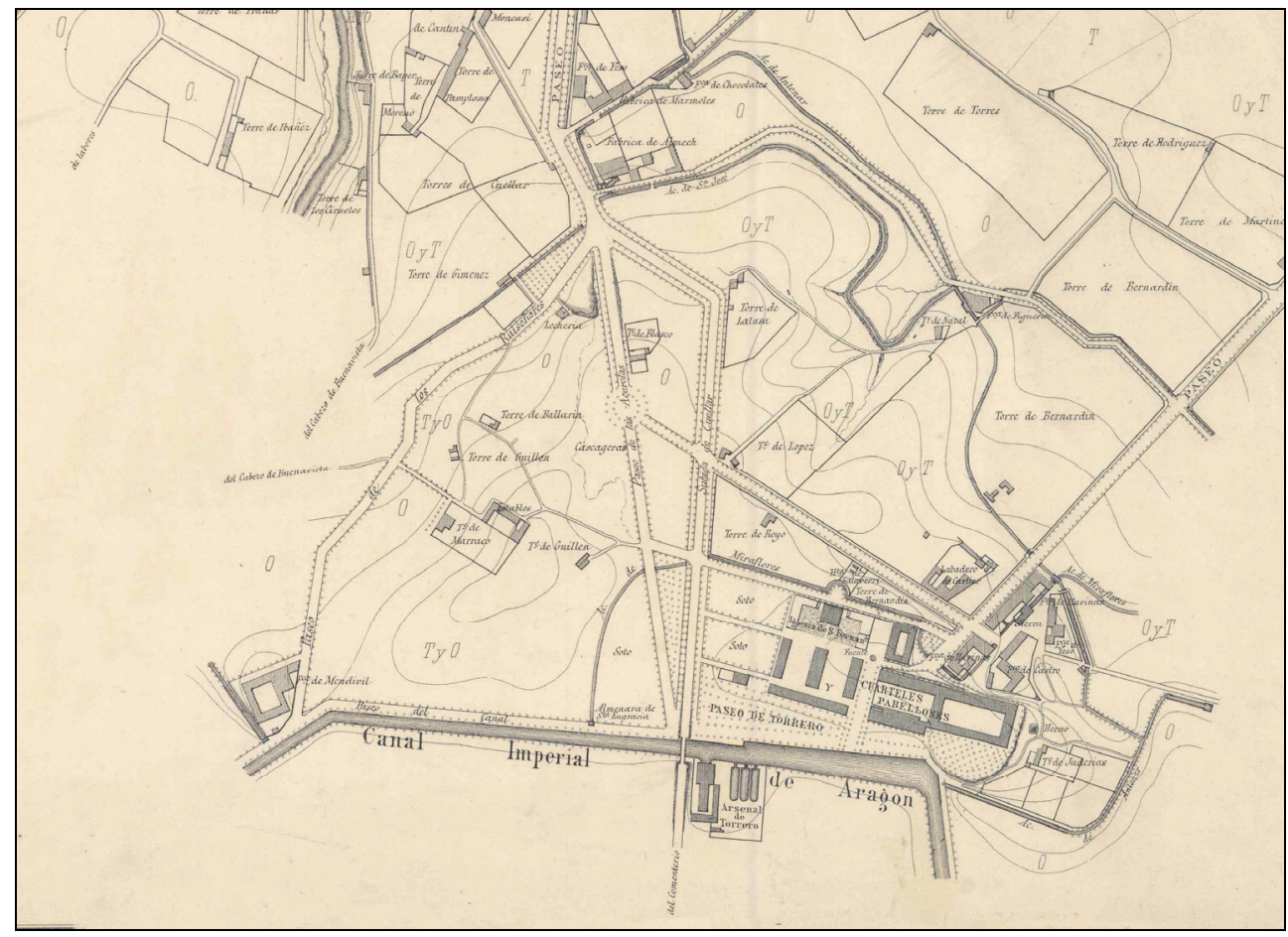

Fig. 3. Plano de Zaragoza levantado por una comisión de oficiales del Cuerpo de E. M. del Ejército en 1869 (detalle), Zaragoza, Depósito de la Guerra, 1872 
El primer paso para la urbanización de la zona fue sin duda la importancia adquirida por el paseo de Torrero, expuesta en enero de 1883 por los concejales Pascual Vicente y Simón Sainz de Varanda ${ }^{1}$ a través una moción para la reforma del citado paseo con la finalidad de mejorar el orden del tránsito de personas y carruajes. En concreto, proponen intervenir en él diferenciando dos partes: desde el puente de Santa Engracia hasta la subida de Cuellar y desde este último punto, siguiendo por el paseo de las Acerolas, hasta el puente de América. Además de ello, se creyó conveniente desmontar el terreno triangular de la subida de Cuellar por ser una superficie rica en grava, materia prima necesaria para la construcción de caminos y otras obras particulares. Una vez estudiado el caso y pasadas las mociones a las secciones correspondientes del Ayuntamiento, el arquitecto municipal, Ricardo Magdalena, presentó el 16 de octubre de 1885 el proyecto de Arreglo del camino de Torrero directamente por los depósitos de agua. Con él, pretendía prolongar y enlazar el camino de Torrero hasta el puente de América por el paseo de las Acerolas y transformar la superficie en jardines para la ciudad.

No era el único proyecto previsto para este espacio urbano, ciertamente la margen derecha de Zaragoza se presentaba como un nuevo espacio burgués que debía de ser reformado y urbanizado. Por este motivo, se introdujo la línea tranviaria $\mathrm{n}^{\mathrm{o}} 4$ de Torrero, inaugurada en septiembre de 1886, la más importante de la red, ya que conectaba la ciudad antigua con el nuevo ensanche hacia el Sur. No obstante, el carril situado junto a los depósitos de agua supuso un condicionamiento para el diseño del futuro parque Pignatelli, ya que recorrió su linde derecho junto a los depósitos de agua hasta los años treinta del siglo XX. En marzo de 1887, el alcalde Sainz de Varanda presenta una moción donde nos informa de cómo la primera parte del proyecto para la prolongación del paseo de Torrero estaba prácticamente terminada, y por ello exige la intervención y la aprobación definitiva de la segunda fase, ya que todavía su expediente se hallaba en trámite:

La glorieta de Pignatelli que servía como punto de solaz y esparcimiento, ha quedado reducida en la actualidad a una pequeña elipse formada entre una serie

\footnotetext{
${ }^{1}$ Simón Sainz de Varanda fue alcalde en dos ocasiones, desde el 13 de julio de 1883 hasta el 8 de febrero de 1884 en la etapa de la Restauración Monárquica y por segunda vez durante la Regencia de María Cristina, desde el 22 de diciembre de 1885 hasta el 1 enero de 1890.
} 
de mayores y menores edificios y sin espacio capaz para el numeroso público que a diario concurre á dicho punto (...) De aquí la necesidad inmediata del pensamiento para preparar y disponer un punto a donde pueda ir el público a esparcir los ánimos sin la aglomeración que se observa en los sitios hoy reducidos por las edificaciones y ninguno para tal objeto como los que afluyen a Torrero².

En la sesión del 22 de marzo de 1887, Gimeno F. Vizarra ${ }^{3}$ añadió otra propuesta para el embellecimiento de Torrero que era la construcción de un parque en las graveras o una zona ajardinada. A esta petición se sumó la emitida por la Sección $2^{a}$, encargada del proyecto del paseo de Torrero, que manifestó la idea de llevar a cabo una intervención completa y por consiguiente, construir un espacio de solaz "especialmente para niños, donde no se moleste a los transeúntes y haya cierto horizonte del que se va careciendo por las muchas edificaciones llevadas a cabo en las afueras".

El proyecto presentado por Magdalena para la prolongación del paseo de Torrero por el de las Acerolas es aprobado definitivamente el 29 de julio de 1887 y publicado en el Boletín Oficial de la Provincia el 13 de agosto para las reclamaciones oportunas del plano propuesto ${ }^{4}$. En este sentido, hay que destacar dos de las demandas interpuestas por los dos propietarios que poseían los terrenos de la antigua torre de Judez, Joaquín Martón y Pablo Buil. El primero, abogado y político de gran relevancia en la vida ciudadana, pronto llegó a un acuerdo con el Concejo, mientras que Pablo Buil, notario de la Curia eclesiástica y abogado, exigió que se modificara el plano en favor de su finca, debido a la importancia que había adquirido su torre de verano, en donde recibía a sus amistades para reunirse en tertulia. También, se expropió en 1889 la fábrica de ladrillos de la Sociedad Hernández, Lagrava y García, donde un año después se inauguró la escuela municipal de Torrero en parte del terreno, y el restante, separado por el paseo de las Acerolas, fue cedido por el Canal Imperial al Ayuntamiento.

\footnotetext{
${ }^{2}$ Archivo Municipal de Zaragoza [A.M.Z]. caja 1.454, exp. 193/1888, Sobre el rebaje y arreglo del camino y paseos de Torrero.

${ }^{3}$ Joaquín Gimeno y Fernández-Vizarra era director del periódico La Derecha, médico, concejal, periodista y político, una de las personas más activas y comprometidas en la sociedad zaragozana de finales del siglo XIX. Fue descrito por Joaquín Martón como "una de las mas perfectas encarnaciones del hombre moderno, para quién la quietud y el reposo equivalen a inercia inexplicable o bochornosa pereza", palabras recogidas en Gimeno y Fernández-Vizarra (1888: 7).

${ }^{4}$ Los terrenos y torre pertenecientes en origen a Mariano Judez, fueron divididos en dos mitades y vendidos por su viuda en 1885 a Joaquín Martón y Pablo Buil.
} 


\subsection{El proyecto para la construcción del parque (1892-1900).}

El desmonte de las graveras de Torrero avanzaba lentamente en la que fuera finca de Joaquín Martón y en los terrenos propiedad del Ayuntamiento antigua fábrica de ladrillos-, mientras la torre de Pablo Buil se había quedado sola en el árido panorama que la rodeaba. Ante la imposibilidad de llegar a un convenio de compra con el propietario, Ricardo Magdalena elaboró detalladamente sus ideales sobre este terreno y de manera oficial ante el Ayuntamiento presentó el Proyecto de jardines a la terminación de Torrero el 29 de febrero de 1892, en el que se recoge la memoria descriptiva y el plano del primer parque de Zaragoza ${ }^{5}$. Un proyecto que siempre tuvo en mente y que nunca abandonó, fruto de una mente progresista conocedora de los planteamientos urbanos más novedosos, en los que se incluían los parques urbanos como agentes beneficiosos para la salud y la higiene, pero sobre todo, como motores de prestigio de las ciudades. Unas aspiraciones de embellecimiento urbano impulsadas en gran medida por la ascendente clase de la burguesía que se vio identificada con su ciudad, símbolo de sus progresos y sus logros. De hecho, toda ciudad de relevancia poseía su parque urbano, en España, Barcelona contaba con el parque de la Ciudadela desde 1888, Valladolid con Campo Grande, cuyo proyecto de acondicionamiento data de 1877 o el parque de Málaga o de la Alameda, una idea que nació en 1876.

En 1892, bajo el encargo de la alcaldía, Ricardo Magdalena daba forma a las sucesivas propuestas de embellecimiento de Torrero impulsadas originalmente por la mente liberal de Sainz de Varanda. La masiva urbanización de los principales espacios urbanos de Zaragoza habían situado en el punto de mira el floreciente paseo de Torrero, el cuál tiempo atrás se había embellecido con la plantación de árboles, sin embargo, su prolongación hasta el Canal, a juicio del arquitecto, debía de completarse con un amplio lugar de esparcimiento y descanso. Si bien, propone que el proyecto debía de realizarse paulatinamente y a medida que las arcas municipales lo permitiesen (Fig. 4). Ricardo Magdalena propone lo siguiente:

Continuando la obra empezada en la que fue torre del Sr. Martón, debería el resto del terreno rebajarse, dándole la rasante de unión entre el nuevo camino y el antiguo, utilizándose con esta operación la grava, piedra y arena resultante,

${ }^{5}$ A.M.Z. caja 955, exp. 50/1905, ff. 5-9. 
en otras obras y arreglando después el suelo para recibir las plantaciones. Estas se disponen según indica el plano, dejando en dos sitios distantes otras tantas plazas bastante espaciosas, protegidas por arbolado para obtener sombra y con gran cantidad de bancos para descanso de los paseantes. La plaza más próxima á la ciudad tiene forma de herradura con un diámetro de 55 metros, y la segunda, de forma casi elíptica cuyo eje mayor es de 60 metros. El resto se halla distribuido en macizos de diferentes formas, separados con paseos de tres metros de latitud, y al final de los jardines se sitúa una pequeña fuente de adorno.

Fig. 4. Proyecto de jardines a la terminación de Torrero (Ricardo Magdalena, 1892) [A.M.Z]

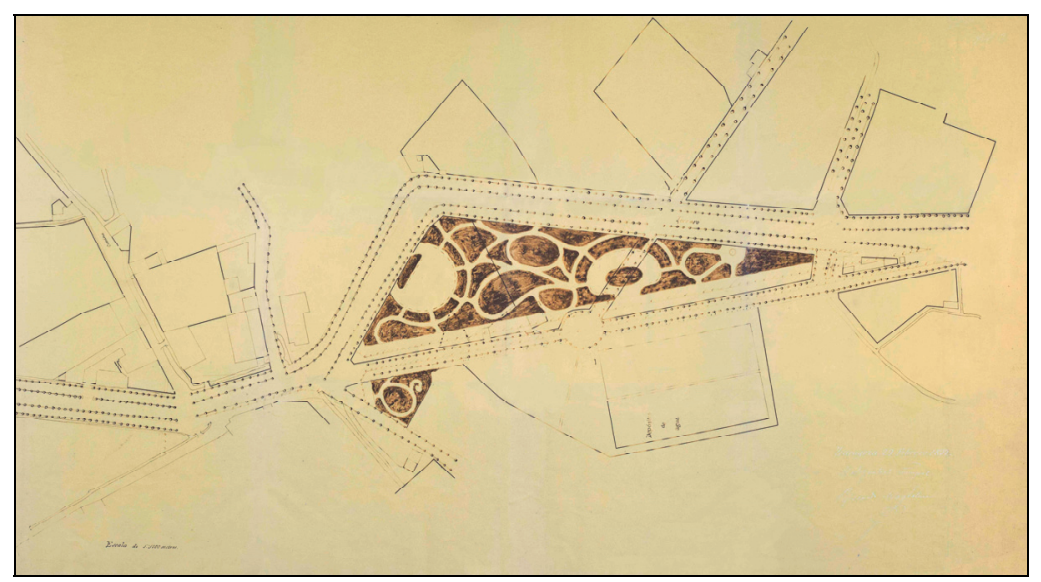

Estima un presupuesto de 20.540 pesetas (jardines, bancos y fuente), sin contar las expropiaciones y desmonte de la gravera ${ }^{6}$.

Desde el punto de vista de la composición y el diseño formal del parque, escoge la corriente más difundida en el siglo XIX, la tendencia paisajista, muy adecuada para el desnivel ascendente de la gravera de Cuellar. Asimismo, el parque paisajístico adoptado por Magdalena era la solución más práctica y económica frente a los complejos sistemas de jardinería clásica, por permitir una libre ordenación de los elementos ornamentales, desligándose del concepto del parterre. El futuro parque de Torrero se concibe como una extensión de libre trazado, en donde los caminos son perfilados sinuosamente en formas

\footnotetext{
${ }^{6}$ En cuanto al diseño de jardines, Ricardo Magdalena tenía experiencia en el asunto, ya que en el año 1883 había presentado el Proyecto de arreglo de la plaza del Pilar para el que incorporaba zonas ajardinadas que ordenaban el interior de la plaza. Con posterioridad, en 1896 elaboraría el Proyecto de jardines en la plaza Salamero, con una concepción y distribución de los espacios verdes similar a la planteada en las graveras de Torrero.
} 
circulares y ovales que confluyen radialmente en plazoletas, como si pretendiera emular en el terreno la estructura interna de las flores y sus pétalos. Delimitados por las calles internas se extienden montículos de césped y espontáneas arboledas, una libertad compositiva de la naturaleza que contrasta con la regularidad de la forma triangular del terreno. La vertiente "naturalista" se estaba proyectando paralelamente en otras ciudades españolas, ejemplo de ello es el jardín del Campo del Moro de Madrid, en el que, aunque no es semejante en extensión y preeminencia al de Zaragoza, su jardinero Ramón Oliva optó por un entramado similar basado en líneas curvas y pequeñas plazas ovales. En este sentido, los dibujos proyectados en los parques paisajísticos siguen concepciones similares en cuanto a su diseño, son rebuscados e imaginativos y las diferencias radican en los accesorios y en el tipo de plantaciones.

Otra de las cuestiones a señalar es la terminología aplicada al proyecto. Se enuncia como "jardines", aunque en sucesivos escritos y en la propia memoria se habla de "parque", este hecho se pudo deber al limitado presupuesto con el que se contaba para el arreglo de la zona mediante la incorporación de un espacio verde, de ahí que en primera instancia se plantease la formación de modestos jardines, sin dejar de lado la aspiración futura de constituir un parque urbano en Torrero. De igual modo, ambos términos van a utilizarse de manera indiferente hasta bien entrado el siglo XX.

Para poder llevar de manera legal la adquisición de la finca de Pablo Buil, la Sección $2^{\underline{a}}$ propone tratar este proyecto de "utilidad pública" y de esta manera, aplicar la ley de 10 de enero de 1879 sobre la expropiación forzosa. Con la aprobación del gobernador civil, Francisco Fernández de Navarrete, se publicó la decisión del Ayuntamiento en el BOPZ el día 20 de abril de 1892, a la que dio respuesta el único afectado. Buil alegó que era un proyecto "caprichoso, estético e inútil" y a esta negativa se unió el ingeniero jefe de Obras Públicas, Juan Llanas. Pero finalmente, el 12 de junio de 1893 se declaraba el Proyecto de jardines a la terminación del paseo de Torrero de utilidad pública. La disputa no terminó y ante el acuerdo, Buil elevó la instancia al Supremo, al Ministerio de Fomento, suplicando que todo lo anterior se declarara nulo, acogiéndose al derecho de propiedad. El director General de Obras Públicas emitió la Real Orden del 5 de noviembre de 1893, en donde manifestó la utilidad pública del ensanche del paseo de Torrero, por ello, se debía expropiar la parte de Buil acordada relativa a este proyecto. Aunque, por otro lado, negó 
la declaración de utilidad pública de los jardines por ser un espacio eminentemente de recreo y de carácter estético ${ }^{7}$.

Una vez expropiado los metros subscritos de la torre de Buil y tras una década de resistencia por parte del propietario, siguiendo los consejos de sus allegados, el 31 de Octubre de 1898 firmó la escritura de venta a favor del Ayuntamiento por el precio de 75.000 pesetas.

En 1899 se instaló la nueva línea de tranvía por la subida de Cuellar hasta la playa de Torrero, donde se enlazaba con el antiguo carril y también se ampliaron los depósitos de agua para el abastecimiento de la ciudad. Una serie de cambios y mejoras en la zona que quedaron reflejados en el Plano de Zaragoza de Dionisio Casañal y Zapatero, elaborado el mismo año. En él, las graveras de Torrero aparecen rotuladas como "terrenos en desmonte" y la ampliación y prolongación del paseo Sagasta por el antiguo paseo de las Acerolas se presenta como una mejora ya acometida (Fig. 5).

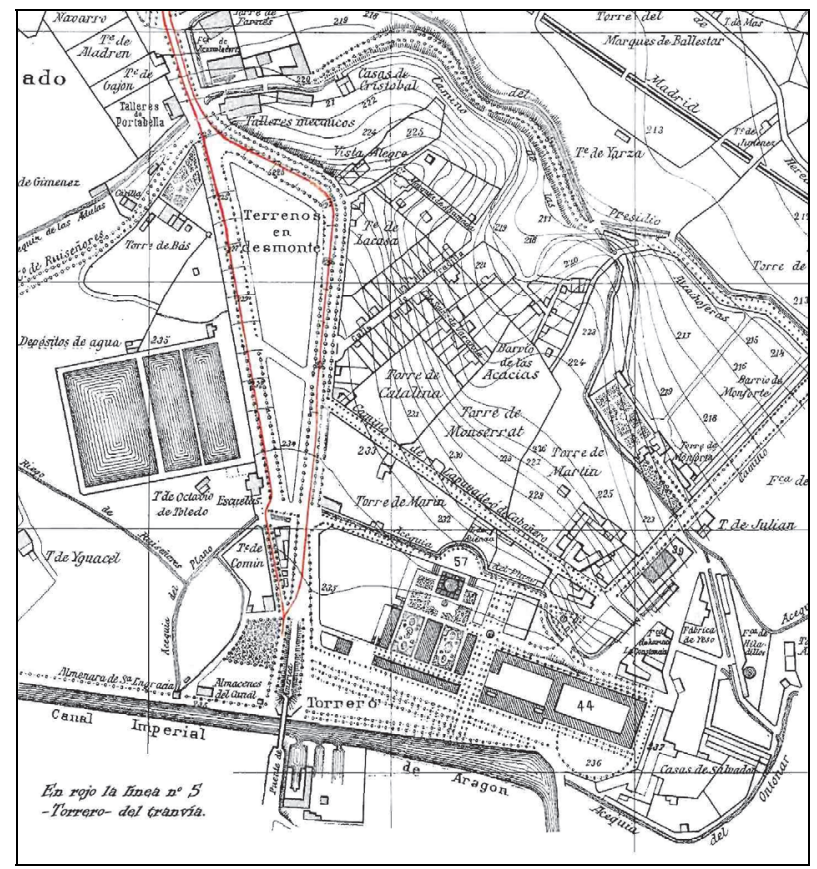

Fig. 5. Plano de Zaragoza (detalle), Dionisio Casañal, 1899 [A.M.Z.]

${ }^{7}$ A.M.Z. caja 567, exp. 339/1898, ff. 57-75. 


\subsection{La consolidación del espacio (1900-1940).}

A principios del siglo XX, las autoridades de la ciudad seguían mostrando sus esperanzas en la construcción de un parque urbano para la población zaragozana. Por ello, la Comisión $5^{\underline{a}}$ solicitó que el jardinero municipal, Francisco Valero, asistiera a la Exposición Internacional de París, celebrada entre el 15 de abril y el 12 de noviembre de 1900:

Como están en proyecto la construcción de nuevos jardines en el casco de la población y un parque en lo que hoy es la gravera de Torrero sería conveniente estudiar todo aquello que sintetizase el moderno gusto y el último adelanto en la materia. Para ello presentase ahora oportunidad, pues juzgando por las noticias que de la exposición universal de París se reciben, en dicho concurso existen preciosidades y cosas curiosas referentes a la jardinería ${ }^{8}$.

A pesar de los intereses municipales de hermosear el terreno y su entorno, todavía quedaba un largo trabajo de desmonte en los terrenos de las graveras. En 1902, el concejal Ojeda presentó una moción en la que instaba a construir el deseado parque $\mathrm{y}$, a esta reivindicación, se sumaron los vecinos de las fincas contiguas que condenaban el estado de las graveras tras la adquisición de la torre de Buil. Las intencionalidades de los propietarios se debatieron en una primera reunión celebrada el 15 de junio de 1903, presidida por el alcalde Laguna y la Sección 5a . En ella, varios vecinos de la zona apoyaron incondicionalmente el proyecto y se comprometieron a reunir dinero con la finalidad de cubrir los gastos de la mejora9. Para hacer frente a los costes, los propietarios anunciaron la creación de una sociedad llamada La Actividad y como representantes de la misma se nombraron a José Salas y Melchor Camón. En la reunión se trató el asunto con una perspectiva de futuro y quedó de manifiesto los intereses económicos que despertaba el parque. Entre sus integrantes, los más destacados fueron Julio Juncosa, Emilio Ostalé, Juan Salinas, José Gascón, Damián Escudero o Mariano Aladrén; todos ellos pertenecientes a la burguesía local zaragozana y vinculados, de una forma u otra, al gobierno local de Zaragoza.

El 2 de Septiembre de 1903 se volvieron a reunir con el dinero recaudado: 8.000 pesetas por parte de los vecinos y 5.000 pesetas subvencionadas por el

\footnotetext{
${ }^{8}$ A.M.Z. caja. 935, exp. 1.062/1900.

${ }^{9}$ Esta reunión es reseñada en El Diario de Avisos. “Mejoras en Torrero", 16-VI-1903, p. 1 y en El Noticiero. "Un parque en Torrero", 16-VI-1903, p. 1.
} 
Ayuntamiento, para el pago de los gastos del desmonte de las graveras (de una superficie de $13.000 \mathrm{~m}^{2}$ ) al contratista de las obras y se fijó su terminación en veinte días, antes de la festividad del Pilar ${ }^{10}$. El propósito era comenzar con las labores de jardinería tras la terminación de las fiestas, donde pasaría a intervenir la sección de Agricultura bajo la dirección técnica del Arquitecto Municipal ${ }^{11}$.

El 10 de octubre de 1903 el Diario de Avisos confirmaba la terminación de la explanación de las graveras y en el mes de noviembre, la Comisión $5^{\text {a }}$ pidió que se llevaran a efecto "el señalamiento de los andenes, la apertura de los hoyos y la plantación del arbolado", sin embargo se acordó terminar la rasante del lado Este, trazar un camino desde el centro hasta el de Lapuyade para los carruajes y plantar césped y arbolado y estrechar los jardines y macizos ${ }^{12}$. Así pues, poco a poco, la antigua gravera se fue convirtiendo en una extensa zona ajardinada, que mucho se alejaba del proyecto originario de 1892.

En 1904, los jardines acogerían en su terreno el esperado monumento a Ramón Pignatelli, cuyo traslado se realizó antes de verano desde la plaza de Aragón - su original emplazamiento - hasta este punto, siendo inaugurado con toda solemnidad el 17 de octubre del mismo año. El 1 de septiembre de este año, el arquitecto Félix Navarro envió una carta al alcalde, Emilio Soteras, para exponerle una idea en torno a la estatua de Pignatelli. En ella, explica como montando en tranvía junto al escultor Carlos Palao imaginaron rodeando al monumento de Pignatelli, jardincillos y una fuente de adorno "de esa experta manera que había visto en el paseo de Sebastián", de la que brotara agua a través de surtidores. La carta es acompañada con un pequeño boceto de la fuente descrita, sin embargo, todavía pasarían varias décadas hasta que la estatua de Pignatelli fuese animada por surtidores de agua ${ }^{13}$.

El 27 de junio de 1905, un artículo del Heraldo de Aragón hace referencia al parque que se estaba conformado alrededor de la estatua de Pignatelli:

\footnotetext{
${ }^{10}$ La relación de cantidades hechas por los subscriptores se publicaron en: El Noticiero. "Parque de Torrero", 16, 22 y 27-IX-1903; Diario de Avisos. "El parque de Torrero", 6-VIII-1903, 23-IX1903 y 10-XI-1903.

${ }_{11}$ Actas Municipales. 4-IX-1903, f. 292.

${ }_{12}$ Actas Municipales. 20-XI-1903, ff. 377-378.

${ }^{13}$ A.M.Z. caja 954, exp. 1921/1904.
} 
A juzgar por las trazas será este un jardincillo inglés con unas palmeras enanas y sus arbustos exóticos. Muy lindo en apariencia, si bien muy costoso e inútil para los que busquen en Torrero sombra refrigerante y consoladora ${ }^{14}$.

Como deja constancia este escrito, para los jardines de la subida de Cuellar se seguían tomando como referencia las propuestas paisajísticas tan apropiadas para el lugar, si bien es cierto que las decisiones tomadas en el terreno, como el llevar a cabo la explanación completa de la gravera o el trazar una línea recta desde el centro hasta Lapuyade, alejaban los ideales de la praxis, ya que esta tendencia de jardinería resultaba inadecuada para la topografía adoptada en la superficie. A principios de 1906 se comenzaban las plantaciones en los jardincillos de Torrero para la ordenación del espacio interior, que hasta este momento había presentado un aspecto "informe"15.

Asimismo, José García Mercadal en 1908, montado en el tranvía vierte una opinión con respecto al parque y manifiesta:

El tranvía después de cruzar un instante entre los edificios de varias industrias, deja a la derecha el paseo Ruiseñores, y corre por la Avenida del siglo XX, pasando rápido por el sequedal que preside la estatua de Pignatelli, llamado pomposamente parque de Torrero, y termina su viaje cerca de un café-merendero, en cuyos veladores algunas personas contemplan sentadas la llanura polvorienta que ante sus ojos se extiende (García Mercadal, 1908: 57).

En el ya conocido como "parque de Torrero", quedaba todavía mucho que hacer. Si atendemos a un plano de la zona de 1911 (Fig. 6), se aprecia como la estructura interna del parque queda trazada a partir de una avenida central que es atravesada por dos caminos trasversales, en cuya intersección se disponen dos plazoletas - en la central se situaba la estatua de Pignatelli-. Todo el perímetro se componía de un paseo que rodeaba el terreno triangular y el espacio libre ya estaba ocupado por vegetación. Como se puede observar, sigue los conceptos clásicos del parque urbano decimonónico, es decir, una extensión de terreno estructurada a partir de un diseño geométrico que ordena de manera artificial los agregados espacios verdes.

Durante la segunda década del siglo XX, el parque Pignatelli se equipó con las infraestructuras necesarias para su funcionamiento, en 1913 se arreglaron

\footnotetext{
${ }^{14}$ Heraldo de Aragón. "El veraneo en Zaragoza: los alrededores de la ciudad", 27-VI-1905, p. 1

${ }^{15}$ Actas Municipales. 2-VI-1904, ff. 205-206.
} 
los andenes más próximos al monumento, se aumentaron las plantaciones y se rebajaron los macizos ajardinados ${ }^{16}$. También se amplió el servicio de iluminación y se instalaron seis farolas en el acceso, situado en la parte baja del terreno, junto al paseo de Sagasta. Las labores de jardinería únicamente se concentraban en la primera parte del parque, desde la terminación del paseo de Sagasta hasta la plazoleta en la que se situaba el monumento a Pignatelli, a partir de aquí se extendían hileras rectas de árboles y césped hasta el vértice del triángulo ${ }^{17}$. Entre 1914 y 1917 se instalaron tuberías y bocas de riego en el perímetro del parque y se conectaron con otras situadas en el camino de Lapuyade y el paseo de Ruiseñores para usos domésticos ${ }^{18}$.

Fig. 6. Detalle de las inmediaciones del parque Pignatelli (ca. 1911) (elaborado por Isabel Yeste).

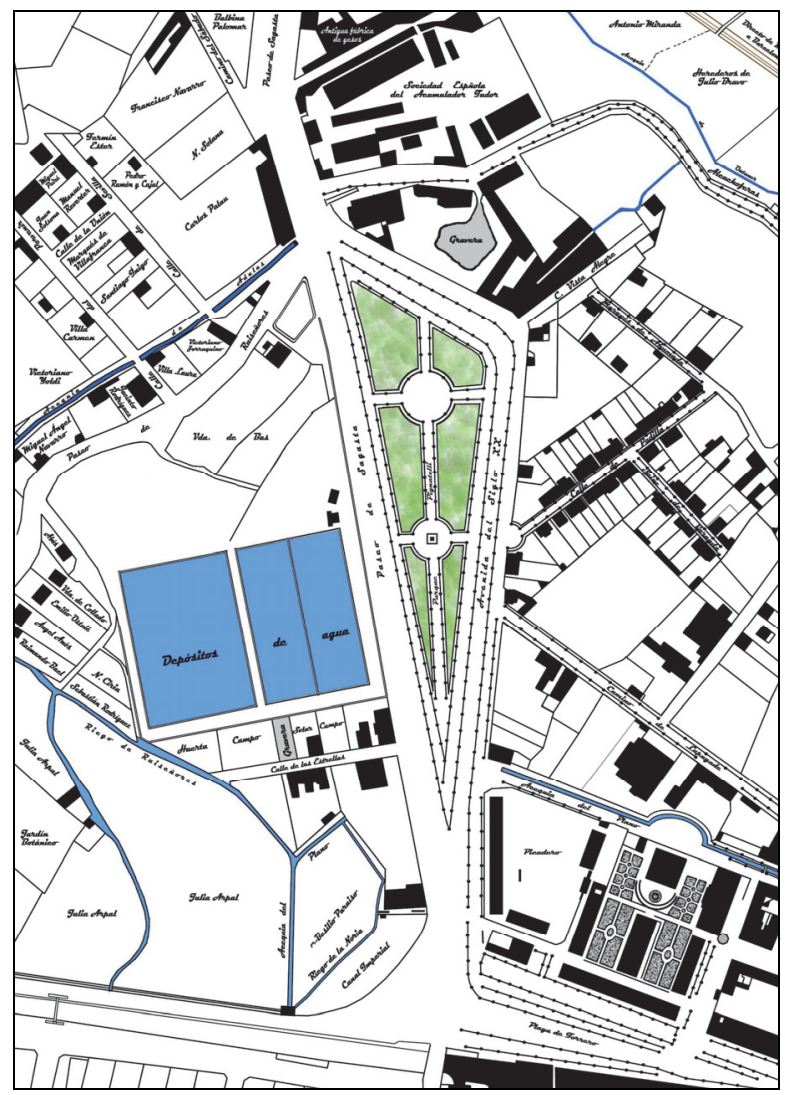

\footnotetext{
${ }^{16}$ A.M.Z. caja 1.853, exp. 654/1913.

17 A.M.Z. caja 1.966, exp. 84/1913.

${ }_{18}$ A.M.Z. caja 2.021, exp. 728/1916 y caja 2.039, exp. 2.882/1917.
} 
En estos momentos se aprobó la idea de crear una fuente en torno al monumento de Ramón Pignatelli, tal y como apuntó el Heraldo de Madrid del 16 de agosto de 1928:

Otra idea espiritual que de llevarse a la práctica, dice mucho a favor de Zaragoza. Estas capitales embellecidas por sus parques, sus jardines y sus estatuas hablan del espíritu viajero de ellas, y el caminante, por mucho tiempo, guarda en su alma un grato recuerdo.... ${ }^{19}$.

A pesar del interés generado por embellecer la estatua de Pignatelli, en 1932 un artículo redactado por los escultores Joaquín y José Albareda para la Revista Gráfica de Cultura Aragonesa, dejaba constancia de cómo finalmente no se habría ejecutado la construcción y ornamentación de la fuente, ya que solicitan su realización mostrando su boceto para otorgar una idea gráfica del resultado (Hermanos Albareda, 1932: 74). (Fig. 7)

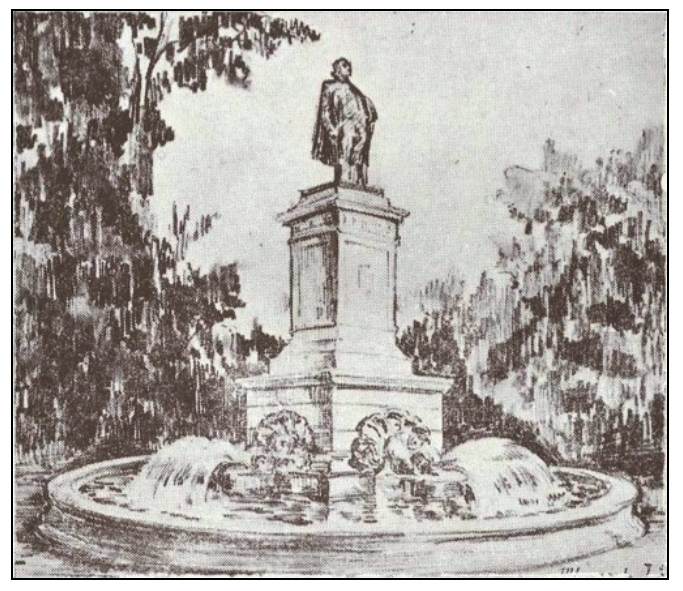

Fig. 7. Boceto de fuente para la estatua de Ramón Pignatelli, Hermanos Albareda, 1932 [Revista Gráfica de Cultura Aragonesa]

A finales de 1929 se acuerda variar la línea tranviaria de Torrero, eliminando el carril que recorría el interior del parque Pignatelli desde 1885, para desplazarla a la prolongación natural del paseo de Sagasta, es decir, por la avenida del Siglo XX hasta la playa de Torrero; la línea dejaría de circular por este tramo en octubre de 1931 y en 1932 se iniciaba la pavimentación de la carretera comprendida entre el parque Pignatelli y los depósitos de agua, conformando así uno de los paseos principales del parque.

${ }^{19}$ Heraldo de Madrid. “Crónicas Aragonesas: La fuente de Pignatelli”, 16-VIII-1928, p. 4. 


\subsection{Las últimas reformas (1940-1985).}

El Anteproyecto de Ordenación General de 1943 redactado por José de Yarza, Regino Borobio y José Beltrán muestra el entorno del parque Pignatelli como una zona residencial heterogénea en la que convivían chalets y bloques plurifamiliares adecuados a las exigencias contemporáneas derivadas del crecimiento de la población y, a la progresiva industrialización que estaba viviendo la ciudad. Estas nuevas necesidades se reflejaron en la construcción de un espacio infantil en el parque Pignatelli con un proyecto de José de Yarza y José Beltrán, aprobado el 22 de noviembre de 1946. Sin duda la incorporación de un parque infantil delata el progreso y el cambio en cuanto a la concepción de los espacios verdes, es un salto del parque decimonónico destinado exclusivamente al deleite estético de la población. El parque, ya no sólo se concibe como un foco de salubridad, sino que se conforma un mundo polivalente de relaciones sociales y diversas actividades adaptadas a las necesidades del mundo contemporáneo. También se acotó el terreno del parque Pignatelli con un muro de mampostería coronado por losas de piedra de Calatorao rematado con una barandilla de protección de hierro. Además, en este momento, se anexionan al parque los jardincillos situados en el paseo de Ruiseñores. Esta misma disposición sigue presentando en la actualidad. Se fijaron cuatro accesos, uno por el paseo de Ruiseñores, otro frente a la calle de Vista Alegre, el intermedio por la plazoleta de la estatua de Pignatelli y el más alto junto a las escuelas. Esta reforma se completó con el arenado de los paseos y el arreglo de los jardines. En cuanto al parque infantil, estaba constituido por "una piscina, pista para patinar, solárium, y aparatos recreativos" 20 .

Las reformas más importantes, todavía reconocibles en la actualidad, se acometerán a partir de los años 60. En septiembre de 1960 es aprobado un proyecto de reforma del parque Pignatelli propuesto por el teniente alcalde y delegado de parques y jardines, José María Franco Espés y Domínguez. Estas obras de acondicionamiento se concibieron con un carácter ornamental, entre ellas, se integraron piezas de cerámica decorativas en el muro de los depósitos, se colocaron bancos, se trasladaron veintisiete farolas de doble brazo que habían iluminado con anterioridad el paseo de la Independencia, se construyó una nueva fuente rodeada de dieciséis columnas en la plazoleta del extre-

\footnotetext{
${ }^{20}$ Archivo Central de Zaragoza [A.C.Z]. caja 200.278, exp. 2933/1946.
} 
mo septentrional y se instalaron fuentes. Los ansiados surtidores reclamados desde principios del siglo XX en el monumento a Ramón Pignatelli se convirtieron por fin en realidad, construyéndose una fuente y un lago de gran sencillez a su alrededor. También se acometieron otras intervenciones como el encintado de los bordillos para delimitar las zonas ajardinadas, el recrecimiento del muro de los depósitos y la reconstrucción de una parte del mismo, trabajos de asfaltado y se instaló una caseta para evacuatorios ${ }^{21}$.

El 17 de mayo de 1961 se inauguraban estas intervenciones en el parque Pignatelli, como informa el Heraldo de Aragón, un acto al que asistieron el alcalde Gómez Laguna, el gobernador Pardo de Santayana, tenientes de alcalde, concejales, José Sinués (procurador de las cortes), empleados del Ayuntamiento y destacadas personalidades de la vida zaragozana ${ }^{22}$. El espacio verde del parque Pignatelli se subordinó a aspectos funcionales, diseñándose y modificándose en torno a los nuevos equipamientos. De este modo, con el tiempo se fue dotando de zonas destinadas para el disfrute y el ocio como la construcción de un quiosco en la parte alta del parque en 1962, y también de otros espacios libres dedicados a los más jóvenes con columpios, toboganes, camas elásticas e incluso atracciones, en actividad desde 1972.

La gran y última reforma del parque llegó con el Proyecto de remodelación Parque Pignatelli presentado en febrero del año 1985 por el de ingeniero municipal de Montes, de cuya memoria cabe extraer y comentar algunas ideas expuestas por el mismo. En el apartado de antecedentes del parque Pignatelli llama la atención la clasificación del diseño originario como "un parque clásico de estilo renacentista" que a consecuencia de la gran afluencia de gente "se ha convertido más bien este espacio en un terreno arbolado con abundantes restos de construcciones, barandillas y otros elementos de un jardín clásico". Quizá esta categorización formalista no es adecuada para este parque, ya que como hemos visto a lo largo de su dilatada historia el espacio que a consecuencia de la situación de principios de siglo se concibió como una arboleda delimitada en un terreno triangular, con el tiempo y a partir sobre todo de los años veinte comenzó a ordenarse mediante jardines acotados.

\footnotetext{
${ }^{21}$ A.C.Z. proyecto 311, exp. 1835/1960.

${ }^{22}$ Heraldo de Aragón. "Ayer quedó reinaugurado el parque de Pignatelli: presenta una fisionomía nueva muy agradable y acogedora", 18-V-1961, p. 4.
} 
Fue precisamente esta clasificación del parque Pignatelli lo que condicionó la última intervención de 1985 y su imagen actual. Fue la continua demanda por parte de los ciudadanos, la idea de recuperar los antiguos depósitos para rehabilitarlos para un museo y la posible instalación de un mercadillo dominical las causas que motivaron la redacción del proyecto ${ }^{23}$.

A partir de estas premisas se reformuló la ordenación interna del parque con una nueva distribución tanto de los jardines como de los paseos peatonales y como se apunta en la memoria "los elementos constructivos se ciñen al estilo clásico del parque, quedando los dos accesos más importantes enmarcados ostensiblemente con elementos arquitectónicos que dan más realce a las entradas". También se proyectaron otros equipamientos como una biblioteca infantil y la colocación de bancos de piedra a semejanza de los que estuvieron situados en esta zona y en el cabezo de Buenavista con cerámicas de publicidad de diversas empresas zaragozanas. Las obras fueron adjudicadas a la empresa Corviam S.A en febrero de 1985 con un presupuesto de 37.692 .518 pesetas.

Comenzando con el diseño interior del parque, atendemos al plano del estado que presentaba antes de la remodelación. La fisonomía del espacio se constituía de manera irregular a partir de macizos ajardinados de diferentes formas y tamaños que conformaban a su vez los espacios libres. Los paseadores se localizaban en el perímetro del parque y en la vía central y toda la superficie quedaba salpicada por árboles, algunos colocados en hileras y otros de manera aleatoria. Se accedía mediante tres accesos, por la plaza de Diego Velázquez, el paseo de Cuellar y la calle de Maestro Estremiana, accesos que se mantienen en el nuevo trazado.

En la reforma emprendida se regulariza toda la superficie, los paseos y las zonas ajardinadas, se amplía la anchura de todas las vías internas y se otorga preeminencia al eje central con una mayor amplitud, en donde se abren las dos plazoletas circulares. El paseo derecho, junto a los depósitos, se divide en dos calles separadas por jardines que unen las dos entradas, por la plaza Diego Velázquez y la calle de Maestro Estremiana y el desnivel del terreno se suaviza con la colocación de escalinatas en los paseos. Para ello, se enrasó todo el terreno de los andadores, se introdujeron nuevos bordillos de hormigón

${ }^{23}$ A.M.Z. caja 18.694, exp. 120/1985 (completa). 
a imitación de la piedra blanca y se pavimentó el suelo con cuatro tipos de baldosa. Lo cierto es que el retorno a una distribución interna de carácter clásico viene dado por necesidades de índole funcional, ya que la línea recta permite la correcta distribución de las infraestructuras y el mobiliario y en general supone un mejor aprovechamiento del terreno.

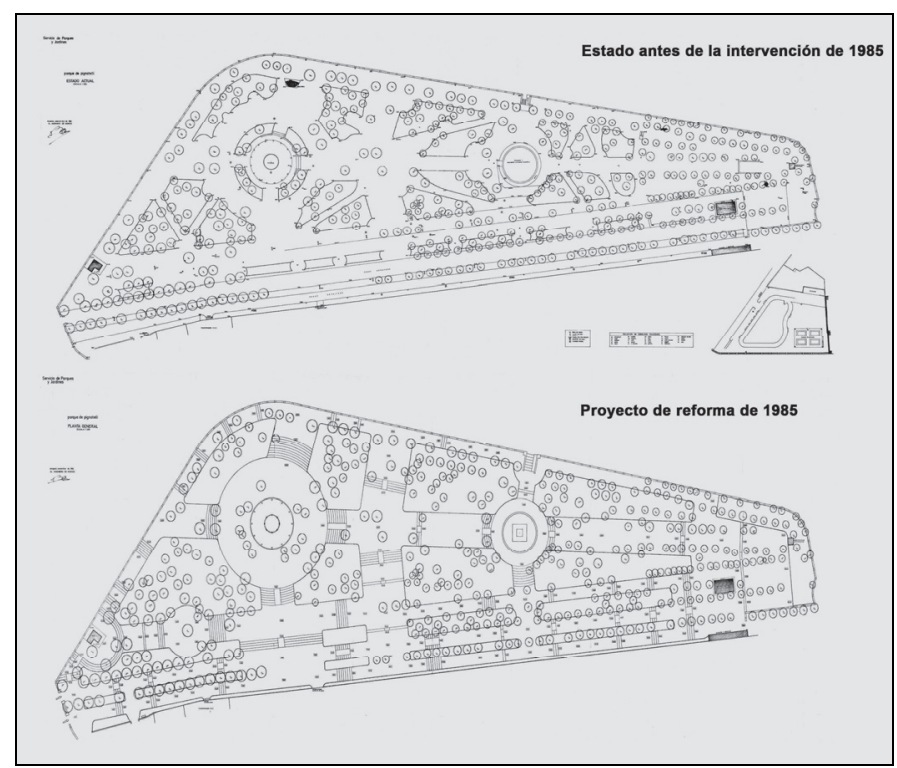

Fig. 8. Estado del parque Pignatelli antes de la intervención y proyecto de reforma, 1985 [A.M.Z]

Entre las remodelaciones más visibles hay que destacar las arquitecturas colocadas en las entradas principales del parque, por la plaza de Diego Velázquez y por el paseo de Cuellar. En la primera se proyectó un acceso monumental de interpretación "clasicista" y para la entrada por el paseo de Cuellar se ideó un pórtico con un frontón triangular. También se construyó la biblioteca de planta octogonal cuyo exterior desprende una variedad de influencias estilísticas como el ladrillo a cara vista, aspectos que recuerdan a construcciones cercanas como la casa del guarda de los depósitos de Torrero.

La reforma se completó con el mejoramiento de la instalación eléctrica y la colocación de nuevas farolas de columna metálica troncocónica con báculo y porta globos, conservando las anteriores. También se instalaron tres fuentes de agua, y desapareció una fuente ornamental que representaba una figura feme- 
nina, probablemente instalada en la reforma de los años sesenta, de la cual se desconoce su autor, aunque sí que se conserva un testimonio fotográfico de la misma. Finalmente no se ubicaron los bancos de propaganda (Fig. 9).

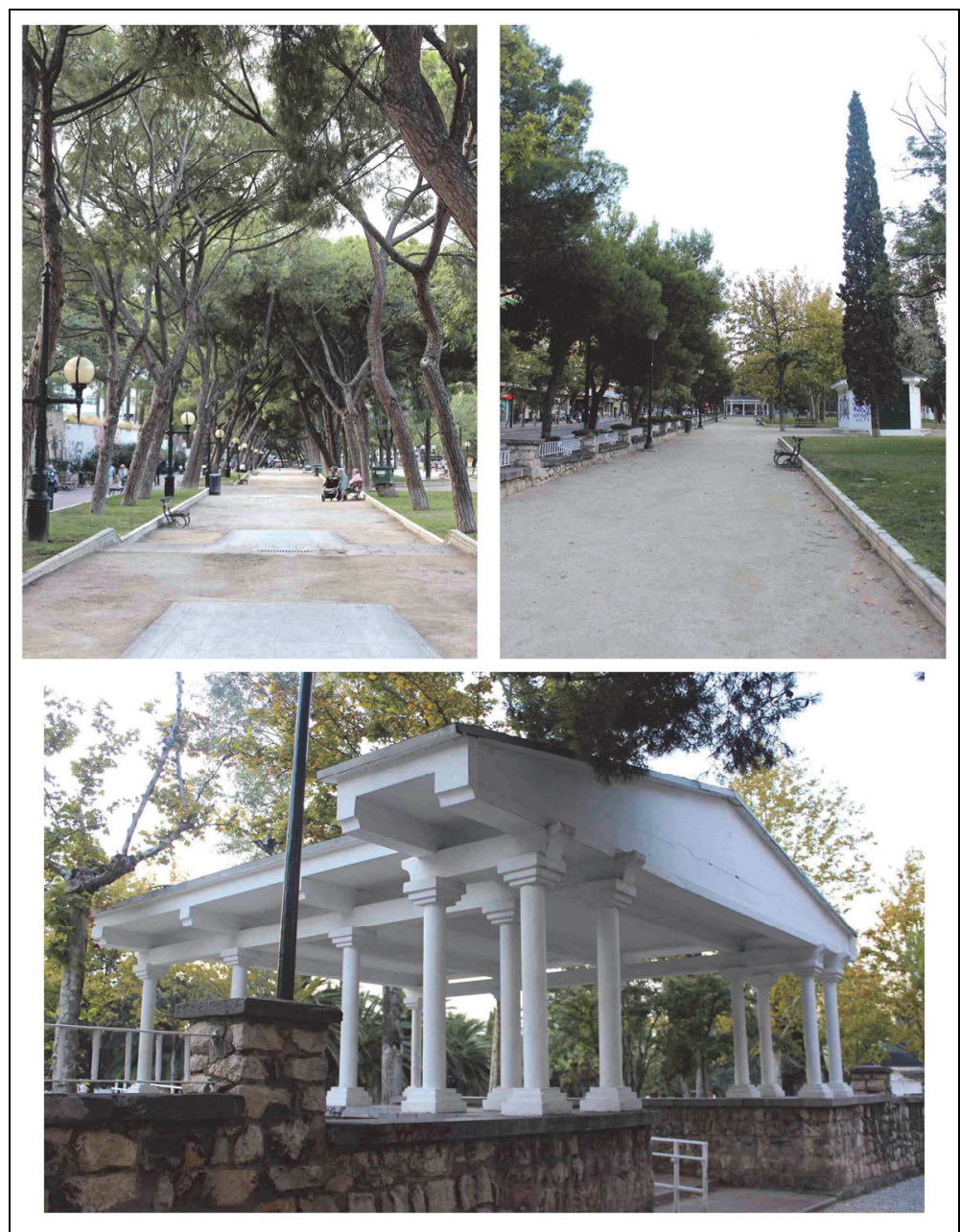

Fig. 9. Andadores y acceso al parque Pignatelli por el paseo de Cuellar (estado actual)

La última gran reforma del parque Pignatelli se concibió bajo los presupuestos más tradicionales del diseño contemporáneo de los espacios verdes, con la vocación de retomar su "trazado originario" y mantener su contexto cultural del entorno urbano. 
El ornato del parque Pignatelli se siguió enriqueciendo en 1987, con la colocación de un busto dedicado al poeta local José María Ferrer "Gustavo Adolfo", realizado por Miguel Cabré Cazcarra, sustituyendo a otro anterior que había sido robado, bajo la promoción de la Peña Solera Aragonesa ${ }^{24}$. Es una escultura de pequeñas dimensiones resuelta de manera naturalista, que trata de resaltar la facciones del retratado, siguiendo la línea de este tipo de monumentos conmemorativos dedicados a figuras ilustres ${ }^{25}$. En la actualidad, es una obra animada por un jardincillo con flores que la rodea, emplazada en uno de los andadores laterales localizados al oeste. No es la única muestra artística que encontramos en el parque, ya que en el muro perimetral que separa el parque de los depósitos de agua, el pintor Ignacio Fortún, realizó en 2006 un mural en el que reflexiona sobre el mundo del teatro, los títeres y la manipulación, de ahí su denominación como "Parque de las Marionetas". Actualmente la obra pictórica ha desaparecido bajo los grafitis callejeros. Este muro forma parte de la iniciativa llamada "Galería Urbana", un proyecto subvencionado por el Ayuntamiento de Zaragoza para la intervención de los artistas en el espacio público, que tiene como finalidad "generar un recorrido muralístico único que pueda sumarse a la oferta cultural y turística de Zaragoza" ${ }^{26}$.

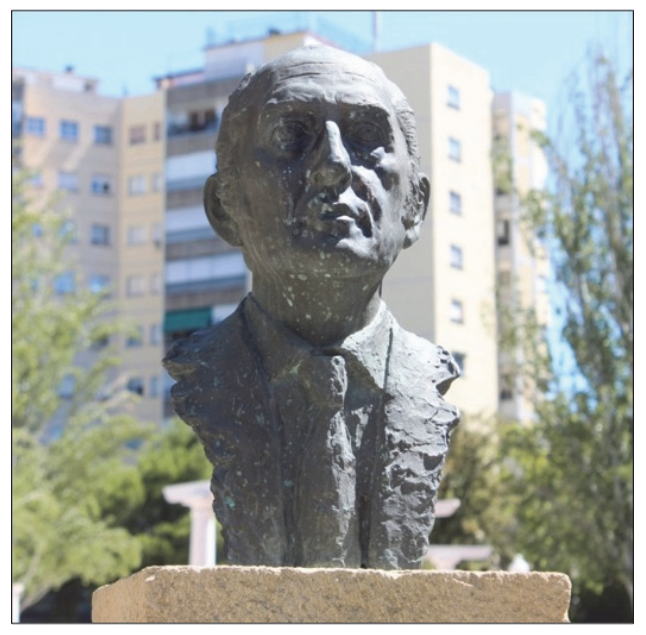

Fig. 10. Busto de José María Ferrer "Gustavo Adolfo", Miguel Cabré Cazcarra, 1987.

\footnotetext{
${ }^{24}$ José María Ferrer Gustavo Adolfo (1917-1984), fue un periodista y locutor de radio aragonés.

${ }_{25}$ Véase, http://www.zaragoza.es/ciudad/artepublico/detalle_ArtePublico?id=104 [Consultada $1 / 03 / 2016]$.

${ }^{26}$ Para más información sobre el proyecto, véase www.galeriaurbana.es [Consultada 1/03/2016]
} 


\section{Conclusiones.}

El primer parque urbano construido en Zaragoza - parque Pignatellipresenta una cronología tardía con respecto a otras ciudades de España. No obstante, como ha quedado evidenciado, los deseos de dotar a la ciudad de Zaragoza de una zona pública verde de manifestaron ya en los años ochenta del siglo XIX. Se pretendió entonces trasladar a la ciudad las tendencias europeas en el ámbito de la jardinería y los parques públicos. También, se ha podido constatar en el trascurso del estudio sobre la historia del parque Pignatelli, como en su construcción tuvieron una presencia destacada los intereses económicos sobre los medioambientales, sanitarios o higiénicos, partiendo de la idea de que la zona Sur podía considerarse privilegiada por la existencia de arbolado en los paseos de Sagasta y Ruiseñores y de espacios verdes en la playa y monte de Torrero. La valoración y el encuentro entre paisaje y ciudad, contribuyó a cambiar sustancialmente el valor referencial del suelo.

Mas allá de los intereses especulativos, el citado parque también fue el resultado de un ideario burgués que trataba de superar los problemas derivados de la sociedad industrial, donde la naturaleza se mostraba como una píldora sanadora que otorgaba un ambiente saludable, al mismo tiempo que embellecía el entorno urbano. Un imaginario en el que la naturaleza no sólo se concebía como un espacio de contemplación, sino que tenía funciones eminentemente prácticas.

Todavía la historia del parque Pignatelli es un capítulo inconcluso, en la actualidad nuevas pretensiones giran en torno al parque más antiguo de la ciudad, aunque son esbozos de futuro en el que se plantea aumentar su superficie por el terreno de depósitos de agua y construir nuevas edificaciones residenciales. De esta forma, se pretende colmatar el vacío existente en el extenso terreno de los depósitos y establecer una conexión directa del paseo de Cuellar y el paseo de Ruiseñores. 


\section{Bibliografía}

Alonso Velasco, J.M. (1971): Ciudad y espacio verde. Servicio de Publicaciones del Ministerio de la Vivienda, Madrid.

HERNÁNDEZ MARTíNEZ, Ascensión (1991-1992): “La planificación urbana a comienzos del siglo XX: la apertura del paseo Sagasta". Artigrama, Zaragoza, núm. 8-9, pp. 435-454.

GARCíA MERCADAL, José (1908). Zaragoza en tranvía. Tipografía de Emilio Casañal. Zaragoza.

GIMENO Y FERNÁNDEZ-VIZARRA, Joaquín (1888): ;Vamos muy despacio!: Zaragoza en 1887, estudio crítico descriptivo. Tipografía La Derecha. Zaragoza.

GUÍA DE ZARAGOZA de 1860 (1860). Imp. Vicente Andrés (Edición Facsímil, Librería General, Zaragoza, 1985).

Hermanos Albareda (1932): “Lo que podría ser el parque Pignatelli”. Revista Gráfica de Cultura Aragonesa, Zaragoza, núm. Abril, p. 74.

VÁzQueZ AstorgA, Mónica y Yeste NAVArRo Isabel (2001): “El gobierno civil de Zaragoza y su sede institucional”. Artigrama, Zaragoza, núm. 26, pp. 743-768.

YESTE NAVARRO, Isabel (2007): “Ideología y urbanismo en la Zaragoza decimonónica”. Artigrama. Zaragoza, núm. 22, pp. 649-669.

http://www.zaragoza.es/ciudad/artepublico/detalle_ArtePublico?id=104

[Consultada 1-3-2016].

www.galeriaurbana.es [Consultada 1/03/2016] 